\title{
ESTUDO COMPARATIVO ENTRE O PROCESSO DE CRIAÇÃO DE EMPRESAS TECNOLÓGICAS E O DE EMPRESAS TRADICIONAIS
}

\section{Cândido Vieira Borges Jr}

Doutor (Ph.D.) em Administração pela HEC Montréal, Canadá

Professor da Universidade Federal de Goiás - UFG

candidoborges@gmail.com

\section{Louis Jacques Filion}

Doutor (Ph.D.) em Empreendedorismo e Sistemas pela HEC Montreal, Canadá

Professor de Empreendedorismo da HEC, de Montreal, Canadá.

louisjacques.filion@hec.ca

\section{Germain Simard}

Mestre em Administração pela École Nationale d'Administration, Paris

Professor da HEC, de Montreal, Canadá.

germain.simard@hec.ca

\section{RESUMO}

Este artigo tem como objetivo comparar o processo de criação de empresas tecnológicas com o as tradicionais e identificar as particularidades do processo percorrido pelo primeiro grupo. Um modelo dividindo o processo de criação em quatro etapas (iniciação, preparação, lançamento e consolidação) foi concebido e usado como quadro de análise. Dois questionários foram respondidos pelos empreendedores de 192 novas empresas, sendo 77 de empresas tecnológicas e 115 de empresas tradicionais. Os resultados da comparação entre os dois grupos indicam que o processo de criação de empresas tecnológicas apresenta certas particularidades, mais especificamente que: (i) o acesso a recursos financeiros assim como a gestão financeira constituem uma grande dificuldade para os empreendedores tecnológicos; (ii) os empreendedores tecnológicos precisam desenvolver suas competências em gestão e em comercialização; (iii) o processo de criação de empresas tecnológicas é mais longo e mais difícil que o das empresas tradicionais; (iv) a análise do mercado representa um desafio para os empreendedores tecnológicos; (v) existe uma diferença significativa entre o processo de criação dos diferentes grupos de empresas tecnológicas, essas diferenças precisam ser consideradas na estruturação de pesquisas futuras e também no planejamento de serviços de apoio aos futuros empreendedores.

Palavras-chave: Empreendedorismo tecnológico. Processo de criação de risco. Empresários de alta tecnología. 


\section{INTRODUÇÃO}

Neste artigo é apresentado o resultado de um estudo comparativo entre o processo de criação de empresas tecnológicas e o processo de criação de empresas tradicionais. No total, 192 novas empresas de todos os setores participaram da pesquisa, entre elas 77 empresas tecnológicas. O objetivo desta estudo foi o de comparar estes dois grupos de pesquisa e assim identificar as particularidades do processo de criação de empresas tecnológicas.

O interesse em analisar a criação de empresas tecnológicas se justifica pelo fato que os setores aos quais estas empresas pertencem, como o setor das tecnologias da informação e comunicação, tem uma participação crescente no comércio mundial e que, além disso, a criação deste tipo de empresa é importante na difusão de novos conhecimentos (Allen \& Stearns, 2004; Aspelund, Berg-Utby \& Skjevdal, 2005).

Apesar dos primeiros estudos sistemáticos sobre o empreendedorismo tecnológico terem sido iniciados anos 60, com os trabalhos de Roberts (1968 e 1969) e em seguida de Cooper (1970 e 1971), o conhecimento disponível sobre o processo de criação de empresa tecnológicas continua incompleto e ainda resta muito a descobrir e a compreender sobre as particularidades da criação deste tipo de empresa (Shane \& Venkataraman, 2003).

Segundo Baruch (1997), os três principais critérios utilizados na literatura para diferenciar as empresas tecnológicas das empresas tradicionais são a taxa de investimento em pesquisa e desenvolvimento (P\&D), o nível de formação dos recursos humanos da empresa e o setor de atividades onde a empresa atua.

Neste artigo foi utilizado o primeiro critério, ou seja, a taxa de investimento em T\&D. Baruch (1997) indica que não existe consenso sobre qual a porcentagem mínima do faturamento da empresa deve ser investido em P\&D para que ela possa ser considerada uma empresa tecnológica, mas ele sugere uma taxa de $5 \%$ ou mais. Foram aqui consideradas como tecnológicas todas aquelas que investem $11 \%$ ou mais de seu faturamento em P\&D.

Após essa introdução, a segunda seção do artigo apresenta o quadro conceitual utilizado para definir e delimitar a pesquisa. A terceira seção descreve a metodologia utilizada para realizá-la. A quarta seção apresenta e analisa os resultados da pesquisa. Finalmente, a quinta seção conclui o artigo sintetizando os principais aspectos da pesquisa.

Revista de Administração e Inovação, São Paulo, v. 7, n. 2, p. 03-21, abr./jun. 2010 


\section{QUADRO DE ANÁLISE: UM MODELO DE CRIAÇÃO DE EMPRESAS ESTRUTURADO EM QUATRO ETAPAS}

O processo de criação de uma nova empresa é dinâmico, complexo e não linear (Bruyat \& Julien, 2001; Delmar \& Shane, 2002; Fayolle \& Filion, 2006). Apesar dessa complexidade, alguns autores do campo do empreendedorismo, objetivando facilitar a compreensão e o estudo do fenômeno, tentam esquematizar este processo dividindo-o por etapas ou fases que explicam o processo de criação de uma nova empresa. Um modelo por etapas clássico é o de Churchill e Lewis (1983). Este modelo, que têm cinco etapas (existência, sobrevivência, sucesso, crescimento e maturidade), não trata, entretanto, apenas da fase de criação da empresa, mas de seu ciclo de vida completo. Outros autores se concentraram especificamente na fase de criação. Eles descrevem o processo de criação da sua fase inicial até o momento em que a empresa é considerada criada. O quadro 1 apresenta dez modelos de criação.

\begin{tabular}{|c|c|c|c|c|c|}
\hline AUTORES & \multicolumn{5}{|c|}{ ETAPAS DO PROCESSO DE CRIAÇÃO } \\
\hline Bhave (1994) & Oportunidade & $\begin{array}{c}\text { Preparação da } \\
\text { tecnologia e criação } \\
\text { da empresa }\end{array}$ & Intercâmbio & & \\
\hline $\begin{array}{c}\text { Clarysse e } \\
\text { Moray (2004) }\end{array}$ & Idéia & Pré-lançamento & Lançamento & Pós-lançamento & \\
\hline $\begin{array}{l}\text { Gasse, Diochon } \\
\text { e Menzies (2002) }\end{array}$ & $\begin{array}{l}\text { Concepção e } \\
\text { preparação }\end{array}$ & $\begin{array}{l}\text { Mobilização de } \\
\text { recursos }\end{array}$ & Lançamento & Operações & \\
\hline $\begin{array}{l}\text { Gelderen, Bosma } \\
\text { e Thurik (2001) }\end{array}$ & Intenção & Fronteiras & Recursos & Intercâmbios & \\
\hline $\begin{array}{l}\text { Hernandez } \\
\quad(2001)\end{array}$ & Iniciação & Maturidade & Decisão & Finalização & \\
\hline Reynolds (2000) & Concepção & Gestação & $\begin{array}{l}\text { Nascimento da } \\
\text { empresa }\end{array}$ & $\begin{array}{l}\text { Crescimento ou } \\
\text { Persistência ou } \\
\text { Abandono }\end{array}$ & \\
\hline $\begin{array}{l}\text { Shook, Priem e } \\
\text { McGee (2003) }\end{array}$ & $\begin{array}{c}\text { Intenção } \\
\text { empreendedora }\end{array}$ & $\begin{array}{l}\text { Procura e descoberta } \\
\text { da oportunidade }\end{array}$ & $\begin{array}{l}\text { Decisão de } \\
\text { explorar }\end{array}$ & $\begin{array}{l}\text { Exploração da } \\
\text { oportunidade }\end{array}$ & \\
\hline Tesfaye (1997) & Iniciação & Aclimatação & Consolidação & Lançamento & Infância \\
\hline Vésper (1990) & Conceito & Planejamento & Implementação & & \\
\hline $\begin{array}{l}\text { Vohora, Wright } \\
\text { e Lockett (2004) }\end{array}$ & Pesquisa & $\begin{array}{l}\text { Modelação da } \\
\text { oportunidade }\end{array}$ & $\begin{array}{c}\text { Pré- } \\
\text { organização }\end{array}$ & Re-orientação & $\begin{array}{l}\text { Retorno } \\
\text { sustentável }\end{array}$ \\
\hline
\end{tabular}

\section{Quadro 1: Dez modelos de criação de empresas}


Cada etapa do processo de criação comporta várias atividades ou eventos. Entre as atividades deste processo mais citadas na literatura, encontram-se a identificação de uma oportunidade de negócios, a reflexão e desenvolvimento da idéia de negócios, a redação do plano de negócios, a mobilização de recursos financeiros, a constituição da equipe empreendedora, o desenvolvimento do produto, a contratação de empregados e a comercialização de produtos (Bhave, 1994; Carter, Gartner, \& Reynolds, 1996; Filion \& Dolabela, 2000; Vésper, 1990).

A partir da combinação das etapas indicadas no quadro 1, com as atividades apontadas no parágrafo precedente, foi elaborado um modelo de análise que definiu e delimitou a pesquisa. Nesse modelo, que é apresentado no quadro 2, as principais atividades do processo de criação de uma empresa são agrupas em quatro etapas: iniciação, preparação, lançamento e consolidação.

\begin{tabular}{|c|c|c|c|c|}
\hline Etapas & Iniciação & Preparação & Lançamento & Consolidação \\
\hline 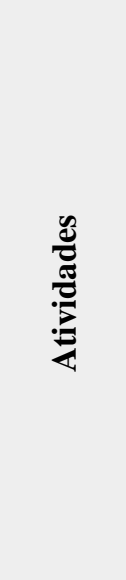 & 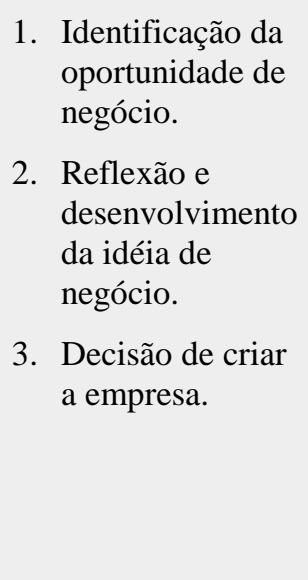 & $\begin{array}{l}\text { 1. Redação do plano de } \\
\text { negócios. } \\
\text { 2. Realização do estudo } \\
\text { de mercado. } \\
\text { 3. Mobilização de } \\
\text { recursos financeiros. } \\
\text { 4. Constituição da } \\
\text { equipe } \\
\text { empreendedora. }\end{array}$ & $\begin{array}{l}\text { 1. Constituição legal da } \\
\text { empresa. } \\
\text { 2. Organização das } \\
\text { instalações e } \\
\text { equipamentos. } \\
\text { 3. Desenvolvimento do } \\
\text { primeiro produto. } \\
\text { 4. Contratação de } \\
\text { empregados. } \\
\text { 5. Realização da } \\
\text { primeira venda. }\end{array}$ & 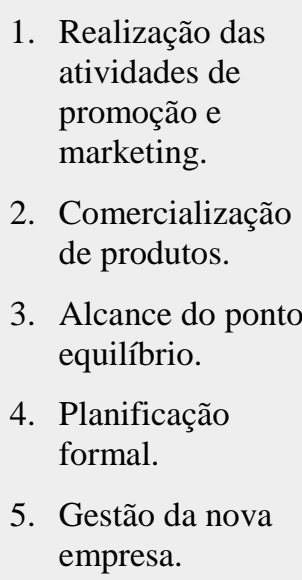 \\
\hline
\end{tabular}

\section{Quadro 2: Etapas e atividades do processo de criação de empresas}

Fontes: Bhave (1994); Carter, Gartner e Reynolds (1996); Delmar e Shane (2002); Reynolds (2000); Reynolds e Miller (1992); Reynolds e White (1997); Gasse, Diochon e Menzies (2004); Gelderen, Bosma e Thurik (2001); Shook, Priem e McGee (2003); Vesper (1990).

\section{METODOLOGIA}

Esta pesquisa, quantitativa, descritiva e exploratória, foi realizada com novas empresas do Québec, Canadá. As empresas participantes da pesquisa deveriam atender a dois critérios: 1) ter entre um e cinco anos de existência; e 2) ter no mínimo quatro empregados. A razão de restringir a participação a empresas com no mínimo um ano de idade se deu pelo objetivo de coletar as informações com empreendedores que já tivessem chegado até a quarta etapa do processo de criação e que poderiam assim descrever a experiência de forma mais completa. Quanto ao limite máximo de cinco anos de existência, seu objetivo foi o de garantir que a 
experiência de criar uma empresa fosse recente e o empreendedor pudesse assim lembrar do maior número de detalhes possíveis sobre ela. O terceiro e último critério - número mínimo de quatro empregados - foi utilizado para diferenciar o grupo de empreendedores pesquisado do grupo de trabalhadores autônomos.

Para construir a amostra, foi solicitada a colaboração de organizações governamentais e para-governamentais que trabalham no apoio aos criadores de empresas. Estas organizações indicaram 641 novas empresas. Após verificação e uma primeira triagem, 175 dessas empresas foram eliminadas. As 466 empresas restantes foram convidadas a participar da pesquisa, 95 recusaram e 170 não atendiam aos critérios indicados acima. A coleta de dados foi então realizada com 201 empresas. No tratamento de dados, nove casos foram eliminados da amostra devido a dados faltantes, o que resultou em uma amostra de 192 novas empresas.

Entre estas 192 novas empresas, 77 são tecnológicas e 115 são tradicionais. Como foi indicado na introdução, o critério utilizado para diferenciar as empresas tecnológicas das empresas tradicionais foi a porcentagem do faturamento gasto com $\mathrm{P} \& \mathrm{D}$, o que foi chamado taxa de investimento em P\&D. Foram consideradas tecnológicas as empresas que investem $11 \%$ ou mais de seu faturamento em P\&D. Estas empresas foram divididas em dois grupos: um grupo com as empresas que investem de $11 \%$ a $40 \%$ em P\&D (47 empresas) e outro com as empresas que investem $41 \%$ ou mais em P\&D (30 empresas). Estes dois grupos foram comparados entre eles e também com as empresas tradicionais (empresas que investem 10\% ou menos de seu faturamento em P\&D). Para facilitar a leitura deste texto, um nome foi dado a cada um dos grupos de empresas (veja tabela 1). As empresas tradicionais serão chamadas de "outras" e as tecnológicas divididas em dois grupos: Tech-01 e Tech-02.

Tabela 1: Nome e número de empresas, segundo a taxa de investimento em P\&D

\begin{tabular}{l|c|c|c|c}
\hline \% do faturamento investido em P\&D & $11 \%$ a $40 \%$ & $41 \%$ ou mais & $11 \%$ ou mais & $10 \%$ ou menos \\
\hline Número de empresas & 47 & 30 & 77 & 115 \\
\hline Nome dado ao grupo & Tech- 01 & Tech- 02 & Tecnológicas & Outras \\
\hline
\end{tabular}

Dois questionários contendo questões majoritariamente fechadas foram utilizados como instrumento de coleta dos dados: questionário "A" e questionário "B". O questionário " $A$ " abordava as informações sobre o empreendedor e a nova empresa, como o número de 
empregados da empresa, sua localização, seu faturamento, o investimento em $P \& D$, a formação e experiências do empreendedor e as fontes de financiamento da empresa. O questionário " $\mathrm{B}$ " trazia questões referentes as atividades realizadas durante o processo de criação da empresa e foi estruturado seguindo o modelo de quatro etapas apresentando anteriormente, no quadro 2. Eram questões que tratavam, por exemplo, da origem da oportunidade de negócios, da constituição da equipe empreendedora, da redação do plano de negócios e da venda de produtos.

Os questionários foram pré-testados em duas etapas. $\mathrm{Na}$ primeira, eles foram apresentados à cinco profissionais que trabalham em organizações de apoio à criação de empresas. Na segunda etapa ele foi respondido por três empreendedores cujas empresas atendiam os critérios da pesquisa. Após cada uma das etapas do pré-teste, as questões dos questionários e a experiência de utilizá-los foram reavaliadas, e as correções necessárias foram feitas.

A coleta dos dados foi realizada entre junho de 2004 e fevereiro de 2005, em duas fases. Em primeiro lugar, o empreendedor respondeu ao questionário "A", que foi enviado por correio eletrônico, por fax ou por correio regular, segundo sua preferência. Em seguida, um membro da equipe de pesquisadores teve um encontro com o empreendedor ao curso do qual o questionário "B" foi respondido. A duração média destes encontros foi de 90 minutos. O tratamento e análise dos dados foram realizados com o auxílio do programa SPSS, inclusive as respostas às questões abertas, que foram codificadas.

\section{APRESENTAÇÃO E ANÁLISE DOS RESULTADOS}

Os resultados da pesquisa serão aqui apresentados seguindo as quatro etapas do modelo de criação de empresas proposto na seção 2: iniciação, preparação, lançamento e consolidação.

\subsection{INICIAÇÃO}

A primeira etapa do processo de criação compreende atividades como a identificação da oportunidade de negócios e a decisão de criar a empresa. Qual é a origem da idéia de negócios? Existem mais idéias originais ou principalmente imitações? Por que os empreendedores decidiram criar a empresa? Essas são algumas das questões que serão respondidas nesta subseção, sempre comparando as novas empresas tecnológicas com as empresas tradicionais.

Revista de Administração e Inovação, São Paulo, v. 7, n. 2, p. 03-21, abr./jun. 2010 


\subsubsection{Origem e originalidade da idéia de negócio}

A tabela 2 e apresenta uma síntese dos resultados sobre a idéia de negócios. Estes resultados indicam que as três primeiras fontes de idéias de negócios dos empreendedores tecnológicos são: (i) o conhecimento do setor de atividade, (ii) conhecimentos tecnológicos do produto e (iii) conhecimentos adquiridos na empresa onde trabalhavam anteriormente. $\mathrm{O}$ item conhecimento tecnológico do produto ou serviço apresenta uma diferença importante quando se compara o resultado dos empreendedores tecnológicos com os outros empreendedores (47\% contra $31 \%)$.

Tabela 2: Origem e originalidade da idéia de negócios, por tipo de empresa

\begin{tabular}{|c|c|c|c|c|}
\hline Origem da ideia de negócios* & Tech-01 & Tech-02 & Tecnológicas & Outras \\
\hline Dos conhecimentos do empreendedor sobre o setor de atividade & $55,3 \%$ & $50,0 \%$ & $53,2 \%$ & $54,8 \%$ \\
\hline $\begin{array}{l}\text { Dos conhecimentos tecnológicos do empreendedor sobre o } \\
\text { produto ou serviço }\end{array}$ & $44,7 \%$ & $50,0 \%$ & $46,8 \%$ & $31,3 \%$ \\
\hline Da empresa onde o empreendedor trabalhava anteriormente & $34,0 \%$ & $50,0 \%$ & $40,3 \%$ & $45,2 \%$ \\
\hline De conversas com potenciais clientes & $21,3 \%$ & $33,3 \%$ & $26,0 \%$ & $33,9 \%$ \\
\hline De conversas com amigos ou família & $17,0 \%$ & $20,0 \%$ & $18,2 \%$ & $31,3 \%$ \\
\hline De conversas com potenciais investidores & $10,6 \%$ & $6,7 \%$ & $9,1 \%$ & $14,8 \%$ \\
\hline De conversas com potenciais fornecedores & $8,5 \%$ & $6,7 \%$ & $7,8 \%$ & $13,9 \%$ \\
\hline Outros & $27,7 \%$ & $26,7 \%$ & $27,3 \%$ & $10,4 \%$ \\
\hline Originalidade da idéia de negócios & Tech-01 & Tech-02 & Tecnológicas & Outras \\
\hline Uma idéia original & $48,9 \%$ & $60,0 \%$ & $53,2 \%$ & $25,2 \%$ \\
\hline Uma adaptação ou imitação de uma outra empresa & $48,9 \%$ & $30,0 \%$ & $41,6 \%$ & $68,7 \%$ \\
\hline Uma adaptação de uma idéia de outra pessoa & $2,1 \%$ & $10,0 \%$ & $5,2 \%$ & $6,1 \%$ \\
\hline
\end{tabular}

Quanto a originalidade da idéia de negócios, como mostra a tabela 2, a maior parte dos empreendedores tecnológicos classifica sua idéia como original. Uma diferença importante dos outros empreendedores, já que no caso deste segundo grupo três quartos dos empreendedores indicam que suas empresas foram construídas a partir da adaptação da idéia de uma outra pessoa ou de uma idéia que é uma adaptação de uma outra empresa. Estes resultados reforçam pesquisas anteriores que mostram que as empresas tecnológicas são mais inovadoras do que as empresas tradicionais. 


\subsubsection{A decisão de criar a empresa}

A decisão de criar a empresa foi tomada pelos empreendedores tecnológicos em média 7 meses (mediana de 4) após a identificação da oportunidade de negócios. Entre os Tech-01 e os Tech-02, existe entretanto uma diferença significativa na mediana: 3 meses para os Tech-01 e 6 meses para os Tech-02. Uma hipótese para explicar este processo decisório um pouco mais longo no caso dos Tech-02 pode ser o grau de complexidade destas empresas, que são intensivas em tecnologia - elas investem $41 \%$ ou mais de seu faturamento em P\&D.

No que diz respeito às razões indicadas para criar a empresa, as pesquisas em empreendedorismo separam a motivação principal para criar um novo negócio entre "por oportunidade" ou "por necessidade", ou em outras palavras, voluntários e involuntários (Filion, 2000). Essa é a sistemática utilizada, por exemplo, nos estudos do GEM - Global Entrepreneurship Monitor (Reynolds, Bygrave \& Autio, 2004).

Em $61 \%$ dos casos de empreendedores tecnológicos, a principal razão para criar a empresa foi "para tirar proveito de uma oportunidade de negócio". Este número é maior no caso dos Tech-02 (77\%, contra 51\% dos Tech-01 e 47\% dos outros). Raros são os empreendedores tecnológicos que criaram a empresa por necessidade (6\%), mas um número significativo (32\%) entre eles escolheram a opção "outros" como motivo principal para criar a empresa. Os empreendedores que marcaram a opção "outros" indicam razões que não são necessariamente econômicas para criar a empresa, como "ter uma empresa familiar", "realizar um desafio", realizar um objetivo pessoal", "fazer o que eu gosto".

\subsection{PREPARAÇÃO}

$\mathrm{Na}$ segunda etapa do processo de criação os empreendedores começam a materializar a concepção da empresa que pretendem criar. Eles redigem o plano de negócios e mobilizam em parte ou totalmente os recursos financeiros necessários para lançar a empresa. Estas atividades são analisadas nesta subseção.

\subsubsection{Plano de negócios}

Quase que a totalidade dos empreendedores tecnológicos (93\%) redigiram um plano de negócios. É um índice semelhante aos outros empreendedores. É preciso, entretanto, enfatizar que esse alto índice de empreendedores que redigiram um plano de negócios pode ser uma conseqüência das características da amostra. Como indicado na seção 3 (metodologia), todos os 
empreendedores que participaram da pesquisa foram indicados por organizações de apoio ao empreendedorismo. Em geral, essas organizações sugerem, ou mesmo exigem, a redação de um plano de negócios. Outras pesquisas que incluem em sua amostra empreendedores que não passaram por organizações de apoio, encontraram um índice de redação do plano de negócios bem menor. Bhidé (2000), por exemplo, em uma pesquisa com empreendedores americanos, averiguou que apenas $28 \%$ redigiram um plano de negócios.

Como é possível constatar na tabela 3, pelo menos $50 \%$ dos empreendedores tecnológicos precisam de duas vezes mais de tempo para redigir o plano de negócios que os outros empreendedores (mediana de 60 dias contra 30 dias no caso dos outros empreendedores). Este tempo a mais pode ser explicado, ao menos em parte, pela complexidade que caracteriza o ambiente de operação das empresas tecnológicas (Albert, 2000; Bernasconi, 2000; Bernasconi \& Moreau, 2003) e pela dificuldade que os empreendedores tecnológicos encontram para fazer a análise do mercado. Sobre este segundo aspecto, $41 \%$ deles contra somente $19 \%$ dos outros empreendedores apresentaram a análise de mercado como sendo a principal dificuldade enfrentada ao redigir o plano de negócios.

Tabela 3: Informações sobre o plano de negócios, por tipo de empresa

\begin{tabular}{l|c|c|c|c}
\hline \multicolumn{1}{c|}{ Tempo que foi necessário para fazer o plano de negócio } & Tech-01 & Tech-02 & Tecnológicas & Outras \\
\hline Média (em dias) & 86 & 81 & 84 & 83 \\
\hline Mediana (em dias) & 55 & 60 & 60 & 30 \\
\hline Principal dificuldade encontrada para fazer o plano de negócios* & Tech-01 & Tech-02 & Tecnológicas & Outras \\
\hline A analise do mercado & $40,5 \%$ & $42,9 \%$ & $41,4 \%$ & $18,9 \%$ \\
\hline O tempo para fazê-lo & $16,7 \%$ & $14,3 \%$ & $15,7 \%$ & $17,0 \%$ \\
\hline O acesso às informações & $16,7 \%$ & $14,3 \%$ & $15,7 \%$ & $17,0 \%$ \\
\hline A elaboração do plano financeiro & $4,8 \%$ & $7,1 \%$ & $5,7 \%$ & $10,4 \%$ \\
\hline Saber como fazê-lo & $2,4 \%$ & $7,1 \%$ & $4,3 \%$ & $17,0 \%$ \\
\hline * Somente as cinco opções mais citadas são indicadas aqui. & & & & \\
\hline
\end{tabular}

\subsubsection{Mobilização dos recursos financeiros}

É possível constatar na tabela 4 que, como indicado pela literatura (Albert, 2000; Gasiglia, Gueye \& Pistre, 2000), as empresas tecnológicas normalmente precisam de mais recursos financeiros para iniciar suas atividades do que as outras empresas. Entre as Tech-02, por exemplo, em $60 \%$ dos casos (contra $43 \%$ no caso das outras) o capital total mobilizado para criar a empresa foi de mais de 100000 dólares canadenses (1 C $\$=\mathrm{R} \$ 1,84)$. 
Outros dados também indicam que a mobilização e gestão de recursos financeiros são mais complexas no caso dos empreendedores tecnológicos, e, em particular, para as Tech-02. Em primeiro lugar, as Tech-02 precisaram de mais tempo para reunir o capital necessário: em média 206 dias (mediana de 105) contra 78 dias em média (mediana de 15 dias) dos empreendedores tradicionais. Em segundo lugar, 63\% dos Tech-02 precisaram rever sua necessidade de capital após o lançamento da empresa (contra $46 \%$ dos outros). Finalmente, as Tech-02 têm uma estrutura mais heterogênea de parceiros financeiros: 67\% das Tech-02 contra 40\% das Tech-01 e $37 \%$ das outras têm três parceiros financeiros ou mais, com uma presença mais forte de sociedades de capital de risco (24\% das Tech-02, $14 \%$ das Tech-01 e $13 \%$ das outras) e de parceiros silenciosos (31\% das Tech-02, $16 \%$ das Tech-01 e $6 \%$ das outras). São considerados parceiros silenciosos os anjos financeiros, parentes ou amigos que não participam das decisões da empresa.

Tabela 4 - Informações sobre a mobilização de recursos financeiros, por tipo de empresa

\begin{tabular}{l|r|r|r|c}
\hline \multicolumn{1}{c|}{ Capital inicial total (m dólares canadenses) } & Tech-01 & Tech-02 & Tecnológicas & Outras \\
\hline O \$ a 25000 \$ & $23,4 \%$ & $13,3 \%$ & $19,5 \%$ & $21,7 \%$ \\
\hline 25001 \$ a 50000 \$ & $8,5 \%$ & $10,0 \%$ & $9,1 \%$ & $13,0 \%$ \\
\hline 50001 \$ a 100000 \$ & $14,9 \%$ & $16,7 \%$ & $15,6 \%$ & $21,7 \%$ \\
\hline 100001 \$ a 250000 \$ & $27,7 \%$ & $30,0 \%$ & $28,6 \%$ & $24,3 \%$ \\
\hline 250001 \$ a 1 Milhão \$ & $10,6 \%$ & $20,0 \%$ & $14,3 \%$ & $13,9 \%$ \\
\hline Mais de 1 Milhão \$ & $14,9 \%$ & $10,0 \%$ & $13,0 \%$ & $5,2 \%$ \\
\hline Tempo que foi necessário para reunir este capital & Tech-01 & Tech-02 & Tecnológicas & Outras \\
\hline Média (em dias) & 67 & 206 & 122 & 78 \\
\hline Mediana (em dias) & 30 & 105 & 60 & 15 \\
\hline
\end{tabular}

\subsubsection{Formação da equipe empreendedora}

Além de ter mais parceiros financeiros, as Tech-02 têm também uma maior presença de equipes empreendedoras: $90 \%$ das Tech-02 (contra 77\% das Tech-02 e 75\% das outras) foram criadas por uma equipe de empreendedores e não por apenas um empreendedor. Essas equipes tem, na maior parte dos casos, dois ou três empreendedores, mas entre as Tech-02 o número de grandes equipes (com quatro ou mais empreendedores) é maior (27\% contra $15 \%$ das Tech-01 e $11 \%$ das outras). 
O alto índice de empreendedorismo por equipe não é exclusivo da amostra estudada. Outros autores, como Aldrich, Carter e Ruef (2004), também já identificaram fenômeno semelhante. Esta crescente ocorrência do empreendedorismo por equipe representa um desafio para o campo do empreendedorismo, pois ele foi construído na premissa de que as empresas são criadas por apenas empreendedor e não por uma equipe de empreendedores. A figura do empreendedor-herói continua a ser vinculada na mídia e na academia, mesmos com os fatos mostrando que o processo empreendedor é concretizado por uma equipe, não por um individuo atomizado.

\subsection{LANÇAMENTO}

A terceira etapa do processo de criação é o lançamento da nova empresa. Nessa etapa são realizadas atividades como o registro legal da empresa, a contratação de empregados e o desenvolvimento do primeiro produto ou serviço.

A tabela 5 abaixo mostra o tempo que foi necessário, após a decisão de criar a empresa, para realizar algumas das atividades da etapa de lançamento. Nela é possível notar que em dois meses, ao menos $50 \%$ dos empreendedores realizam o registro legal da empresa. É possível constatar também que nos primeiros meses do projeto, são os empreendedores que realizam todas as tarefas do novo negócio, pois a contratação do primeiro empregado só acontece de 6 a 12 meses após o início do processo de criação. De fato, $26 \%$ das empresas tecnológicas começam suas atividades formais sem nenhum empregado e somente $17 \%$ entre elas o fazem com 6 empregados ou mais.

Tabela 5: Duração das atividades da etapa de lançamento, por tipo de empresa

\begin{tabular}{|l|c|c|c|c|c|}
\hline \multicolumn{2}{|c|}{ Atividade (em meses)* } & Tech-01 & Tech-02 & Tecnológicas & Outras \\
\hline \multirow{2}{*}{ Constituição legal da empresa } & Média & 5 & 5 & 5 & 7 \\
\cline { 2 - 6 } & Mediana & 1 & 4 & 2 & 2 \\
\hline \multirow{2}{*}{ Contratação do primeiro empregado } & Média & 11 & 10 & 9 & 10 \\
\cline { 2 - 6 } & Mediana & 6 & 6 & 5 \\
\hline \multirow{2}{*}{ Realizar a primeira venda } & Média & 11 & 18 & 13,5 & 10 \\
\cline { 2 - 6 } & Mediana & 6 & 14 & 8 & 5 \\
\hline
\end{tabular}


Os fatores que os empreendedores tecnológicos consideraram mais importantes para escolher a localização da empresas se assemelham aos fatores que os empreendedores tradicionais priorizam. Nos dois casos, os fatores mais importantes foram a qualidade de vida da região e a proximidade da residência. Todavia, existem duas diferenças entres estes dois grupos. A primeira delas é que, diferentemente dos outros empreendedores, os empreendedores tecnológicos consideraram importante a disponibilidade de trabalhadores qualificados na região. A segunda é que a proximidade do mercado e dos clientes e a disponibilidade de espaços industriais e comerciais é considerado importante pelos outros empreendedores, mas não pelos empreendedores tecnológicos.

Contrariamente o que poderia ser esperado, o acesso aos laboratórios de pesquisa e desenvolvimento não foi indicado pelos empreendedores tecnológicos como sendo um fator importante para a escolha da localização da empresa. Em uma escala de 1 (não é importante) até 5 (muito importante), a média de avaliação deste fator foi "1" (não é importante) e a mediana foi "2" (pouco importante). É importante ressaltar que importância aqui analisada é a dos fatores de localização no começo da vida da empresa. A importância destes fatores pode ser diferente em um momento de re-localização ou crescimento, quando a empresa estiver em um novo estágio de desenvolvimento.

Os empreendedores Tech-02 levam mais tempo para finalizar o desenvolvimento do primeiro produto que os demais empreendedores. Eles precisam, em média, 17 meses para completar esta atividade, enquanto os Tech-01 levam 12 meses e os outros 11 meses (mediana de 10,8 e 5 meses respectivamente).

Esse prazo mais longo pode ser explicado em parte pelos obstáculos que os empreendedores encontram no caminho. Quando questionados sobre qual foi a principal dificuldade encontrada para desenvolver o primeiro produto, somente $3 \%$ dos Tech-02, contra $19 \%$ dos Tech-01 e $27 \%$ dos outros responderam "nenhuma dificuldade". As dificuldades mais citadas pelos empreendedores tecnológicos foram de ordem financeira, como a falta de recursos para adquirir os equipamentos necessários ou contratar pessoal qualificado.

\subsection{CONSOLIDAÇÃO}

O processo de consolidação de uma nova empresa é longo, especialmente para os empreendedores tecnológicos. Em média, eles precisam de 36 meses para alcançar o ponto de equilíbrio financeiro. Mais especificamente, 31,5 meses para as Tech-01, 45 meses para as Tech- 
01 e 27 meses para as outras empresas. Mas é na comparação das medianas que encontramos diferenças maiores entre as empresas tecnológicas e as tradicionais. A mediana das tecnológicas é o dobro da mediana das empresas tradicionais: 34 meses contra 16 meses. Ou seja, as empresas tecnológicas levam o dobro do tempo para alcançar o ponto de equilibro. Essa mediana é ainda maior para as Tech-02: 47 meses.

\subsubsection{Gestão da nova empresa}

Os empreendedores tecnológicos precisam fazer um pouco de tudo na empresa que criaram. Eles ocupam $28 \%$ do seu tempo com a gestão administrativa e financeira, $22 \%$ com a comercialização, $19 \%$ com pesquisa e desenvolvimento, $10 \%$ na gestão das operações e $21 \%$ com as outras funções. Este resultado sobre as funções que os empreendedores tecnológicos realizam ganha ainda mais relevância quando confrontados com os dados sobre as experiências e as formações que eles tinham antes de criarem a nova empresa. É possível constatar na tabela 6 que os empreendedores tecnológicos tinham um baixo número de cursos realizados e de anos de experiência nas diferentes áreas da administração. Ao menos $50 \%$ dos empreendedores tecnológicos não tinham, antes de criar a empresa, feito um curso de marketing, vendas ou gestão das operações.

\section{Tabela 6: Anos de experiência e formação nas áreas da administração antes de criar a empresa, por tipo de empresa}

\begin{tabular}{l|c|c|c|c}
\hline \multirow{2}{*}{\multicolumn{1}{c}{ Área da administração }} & \multicolumn{3}{c}{ Anos de experiência na área (mediana) } \\
\cline { 2 - 5 } & Tech-01 & Tech-02 & Tecnológicas & Outras \\
\hline Marketing ou vendas & 1,5 & 1,0 & 1,3 & 2,0 \\
\hline Contabilidade ou gestão financeira & 4,0 & 2,0 & 3,0 & 0 \\
\hline Produção ou gestão das operações & 3,0 & 4,0 & 3,0 & 5,0 \\
\hline Gestão dos recursos humanos & 4,5 & 4,0 & 4,5 & 4,0 \\
\hline P\&D, gestão tecnológica ou inovação & 1,5 & 4,0 & 3,0 & 0 \\
\hline \multirow{2}{*}{ Área da administração } & \multicolumn{2}{|c|}{ Empreendedores sem nenhum curso na área (\%) } \\
\hline Marketing ou vendas & Tech-01 & Tech-02 & Tecnológicas & Outras \\
\hline Contabilidade ou gestão financeira & $46,7 \%$ & $57,7 \%$ & $50,7 \%$ & $60,0 \%$ \\
\hline Produção ou gestão das operações & $37,8 \%$ & $37,0 \%$ & $37,5 \%$ & $51,4 \%$ \\
\hline Gestão dos recursos humanos & $57,8 \%$ & $46,2 \%$ & $53,5 \%$ & $65,1 \%$ \\
\hline P\&D, gestão tecnológica ou inovação & $46,7 \%$ & $57,7 \%$ & $50,7 \%$ & $63,9 \%$ \\
\hline
\end{tabular}


Estes resultados sobre a formação e experiências dos criadores de empresas tecnológicas confirmam a literatura (Albert, 2000; Gartner, Starr \& Bhat, 1999; Jones-Evans, 1997) que indica que, em geral, os empreendedores tecnológicos precisam melhorar suas competências em gestão, especialmente nos aspectos ligados ao marketing e a gestão financeira.

\section{CONCLUSÃO}

Este artigo apresentou e analisou os dados do processo de criação de 192 empresas, sendo 77 empresas tecnológicas e 115 tradicionais. As empresas tecnológicas foram divididas em dois grupos: (i) empresas que investem entre 11 e $40 \%$ de seu faturamento em P\&D (chamadas de Tech-01) e (ii) empresas que investem $41 \%$ ou mais em P\&D (chamadas de Tech02). A análise e comparação do processo de criação percorrido por estes diferentes grupos possibilitou a identificação de aspectos importantes inerentes à criação de empresas tecnológicas. Estes aspectos são sintetizados na seguir.

A primeira constatação é que a criação de empresas tecnológicas apresenta certas particularidades em relação a criação de empresas tradicionais. Todavia, são as empresas do tipo Tech-02, as que investem mais em P\&D, que apresentam as diferenças mais significativas. Em algumas atividades do processo de criação, as empresas do tipo Tech-01 se assemelham mais às empresas tradicionais que às Tech-02. As Tech-01 e as Tech-02 constituem, na verdade, dois grupos diferentes: tratam-se de empresa de baixa tecnologia de uma parte (Teh-01) e de empresas de alta tecnologia de outra parte (Tech-02). O modelo de criação da empresa, e, em seguida, de seu desenvolvimento, não é o mesmo. O grau de complexidade do processo também não. Essa constatação corrobora outros estudos (Christensen, Ulhoi \& Neergaard, 2001; Colombo \& Delmastro, 2001) que já tinham mostrado diferenças significativas entre empresas tecnológicas de diferentes setores tecnológicos.

Uma conseqüência destas diferenças constatadas entre as Tech-01 e Tech-02 é que as empresas tecnológicas não podem ser tratadas de forma única. Existem diferenças significativas entre o grupo de empresas tecnológicas que investe pesadamente em P\&D e aquelas que, mesmo pertencendo a setores tecnológicos, investem menos em P\&D e tem um comportamento, durante o processo de criação que mais se assemelha às empresas tradicionais. Essas diferenças precisam ser consideradas na estruturação de pesquisas futuras e também no planejamento de serviços de apoio aos futuros empreendedores.

Revista de Administração e Inovação, São Paulo, v. 7, n. 2, p. 03-21, abr./jun. 2010 
Uma outra constatação é a que os empreendedores tecnológicos precisam desenvolver ainda mais suas competências em gestão, em finanças e em comercialização. Além das atividades de $\mathrm{P} \& \mathrm{D}$, o empreendedor tecnológico desempenha várias funções ligadas à gestão da empresa e a comercialização de seus produtos e serviços. Antes de criar a empresa, os empreendedores pesquisados tinham uma formação, em geral, incompleta, e uma experiência de mercado e de gestão insuficiente em setores vitais, como o marketing.

Finalmente, o processo de criação de empresas tecnológicas é mais longo e mais difícil que o das empresas tradicionais. A necessidade de desenvolver uma tecnologia, as características do mercado que elas exploram e a necessidade de recursos que elas têm, torna a tarefa dos empreendedores tecnológicos mais complexa, em especial no caso das Tech-02, que são empresas intensivas em tecnologia.

\section{REFERÊNCIAS}

Albert, P. (2000). La création d'entreprises de haute technologie. Dans T. Verstraete (Éd.). Histoire d'entreprendre - Les réalités de l'entrepreneuriat (pp. 149-160). Paris : EMS.

Aldrich, H. E. (2000). Entrepreneurial strategies in new organizational population. Dans R. Swedberg. (Éd.), Entrepreneurship : The social science view (pp. 211-228). New York : Oxford University Press.

Aldrich, H., Carter, N. M., \& Ruef, M. (2004). Teams. In W. B. Gartner, K. G. Shaver, N. M. Carter \& P. D. Reynolds (Eds.), Handbook of entrepreneurial dynamics : The process of business creation (pp. 299-310). Thousand Oaks: Sage.

Allen, K., Stearns, T. (2004). Technology entrepreneurs. Dans W. B. Gartner, K. G. Shaver, N. M. Carter, \& P. D. Reynolds (Éds.), Handbook of entrepreneurial dynamics - The process of business creation (p. 438-448). Thousand Oaks : Sage Publications.

Aspelund, A., Berg-Utby, T., Skjevdal, R. (2005). Initial resources' influence on new venture survival : A longitudinal study of new technology-based firms. Technovation, 25, p. 13371347.

Autio, E. (2005). GEM 2005 Report on high-expectation entrepreneurship. Global Entrepreneurship Monitor. Récupéré le 13 décembre 2005 de www.gemconsortium.org

Baruch, Y. (1997). High technology organization - what it is, what it isn't. International Journal of Technology Management, 13, p. 179-199. 
Bernasconi, M. (2000). Les modèles de développement des entreprises high tech. Dans M. Bernasconi, \& M. Monsted (Éds), Les start-up high tech - Création et développement des entreprises technologiques (pp. 59-75). Paris : Dunod.

Bernasconi, M., Moreau, F. (2003). L'évolution du projet des jeunes entreprises technologiques innovantes au cours des premières années : une méthode d'appréciation du cheminement stratégique. Revue Internationale P.M.E., 16(3-4), p. 11-29.

Bhave, M. P. (1994). A process model of entrepreneurial venture creation. Journal of Business Venturing, 9, p. 223-242.

Borges, C., Simard, G., Filion, L. J. (2005a). Création d'entreprise - Examen de la documentation. Cahier de recherche 2005-02, Chaire d'entrepreneuriat Rogers -J.-A.Bombardier, HEC Montréal.

Borges, C., Simard, G., Filion, L. J. (2005b). Entreprendre au Québec, c'est capital. Résultats de recherches sur la création d'entreprises. Cahier de recherche 2005-03, Chaire d'entrepreneuriat Rogers -J.-A.-Bombardier, HEC Montréal.

Borges, C., Simard, G., Filion, L. J. (2005c). Création d'entreprises technologiques - Rapport de recherche. Cahier de recherche 2005-13, Chaire d'entrepreneuriat Rogers -J.-A.-Bombardier, HEC Montréal.

Bruyat, C., Julien, P. A. (2001). Defining the field of research in entrepreneurship. Journal of Business Venturing, 16, p. 165-180.

Carter, N. M., Gartner, W. B., \& Reynolds, P. D. (1996). Exploring start-up event sequences. Journal of Business Venturing, 11, p. 151-166.

Christensen, P. V., Ulhoi, J. P., Neergaard, H. (2001). The entrepreneurial process in high-tech and knowledge-based sectors in Denmark. Récupéré le 15 mars 2003 de http://www.org.hha.dk/org/lok/Pdf/WP3_2001.pdf

Churchill, N. C., \& Lewis, V. L. (1983). The five stages of small business growth. Harvard Business Review, 61(3), 30-39.

Clarysse, B., \& Moray, N. (2004). A process study of entrepreneurial team formation: the case of a research-based spin-off. Journal of Business Venturing, 19(1), 55-79.

Colombo, M., Delmastro, M. (2001). Technology-based entrepreneurs : Does internet make a difference? Small Business Economics, 16, p. 177-190.

Cooper, A. C. (1970). The Palo Alto experience. Industrial Research, Mai, p. 58-60.

Cooper, A. C. (1971). Spin-offs and technical entrepreneurship. IEEE Transactions on Engineering Management, EM-18, p. 2-6. 
Delmar, F., Shane, S. (2002). What firm founders do: a longitudinal study of the start-up process. Dans W. D. Bygrave, C. G. Brush, P. Davidsson, J. Fiet, P. G. Greene, R. T. Harrison, M. Lerner, G. D. Meyer, J. Sohl \& A. Zacharakis (Éds.). Frontiers of Entrepreneurship Research 2002 (p. 632-645). Wellesley : Babson College.

Dornelas, J. C. A. (2001). Empreendedorismo, transformando idéias em negócios. São Paulo: Campus.

Fayolle, A., \& Filion, L. J. (2006). Devenir entrepreneur : des enjeux aux outils. Paris: Village Mondial.

Filion, L. J. (2000) Travail autonome : des volontaires et des involontaires. Vers de nouvelles formes de pratiques entrepreneuriales. Revue internationale de gestion, 24(4), 48-56.

Filion, L. J., Dolabela, F. (Ed.) (2000). Boa idéia! E agora? São Paulo: Cultura editores.

Gartner, W., Starr, J., Bhat, S. (1999). Predicting new venture survival : An analysis of "Anatomy of a Start-up" cases from Inc. magazine. Journal of Business Venturing, 14, p. 215 232.

Gasse, Y., Diochon, M., Menzies, T. V. (2002a) Les entrepreneurs naissants et la poursuite de leur projet d'entreprise: une étude longitudinale. Communication présentée au Gème Congrès international francophone sur la PME, Montréal.

Gasse, Y., Diochon, M., Menzies, T. V. (2002b). Entrepreneurs naissants au Canada: la trame des deux premières années. Communication présentée au Colloque annuel du CCBE/CCPME 2002, Halifax.

Gasse, Y., Diochon, M., Menzies, T. V. (2003). Les entrepreneurs naissants dont l'entreprise est devenue opérationnelle et les autres: comparaisons lors de la conception du projet d'entreprise. Communication présentée au Colloque annuel de l'ASAC 2003, Halifax.

Gasse, Y., Diochon, M., Menzies, T. V. (2004). Les entrepreneurs émergents dont l'entreprise est devenue opérationnelle et les autres : comparaisons lors de la conception du projet d'entreprise. Journal of Small Business \& Entrepreneurship, 17(2), p. 117-134.

Gasiglia, C., Gueye, S., Pistre, N. (2000). La valorisation, enjeu central de la logique financière des start-up. Dans M. Bernasconi, \& M. Monsted (Éds), Les start-up high tech - Création et développement des entreprises technologiques (p. 167-179). Paris : Dunod.

Gelderen, M., Bosma, N., Thurik, R. (2001). Setting up a business in the Netherlands: who starts, who gives up, who is still trying. Dans W. D. Bygrave, E. Autio, C. G. Brush, P. Davidsson, P. G. Greene, P. D. Reynolds, H. J. Sapienza (Éds.). Frontiers of Entrepreneurship Research 2001 (p. 80-90). Wellesley : Babson College.

Hernandez, É.-M. (2001). L'entrepreneuriat - Approche théorique. Paris: L'Harmattan. 
Jones-Evans, D. (1997). Technical entrepreneurship, experience and the management of small technology-based firms. Dans D. Jones-Evans, \& M. Klofsten (Éds), Technology, innovation and enterprise - The European experience (p. 11-60). London : Macmillan Press.

Reynolds, P. D. (2000). National panel study of U.S. business start-ups : background and methodology. Dans Katz, J. A. (Éd.), Databases for the Study of Entrepreneurship (pp. 153227). Amsterdam, JAI/Elsevier.

Reynolds, P., Bygrave, W., \& Autio, E. (2004) GEM 2004 Summary Report, Global Entrepreneurship Monitor.

Reynolds, P., Miller, B. (1992). New firm gestation: conception, birth, and implications for research. Journal of Business Venturing, 7, p. 405-417.

Reynolds, P. D., White, S. B. (1997). The Entrepreneurial Process : economic growth, men, women, and minorities. Westport, Connecticut : Quorum Books.

Roberts, E. (1968). Entrepreneurship and technology: A basic study of innovators. Research Management, 11, p. 249-266.

Roberts, E. (1969). Entrepreneurship and technology. Dans W. Gruber, \& D. Marquis (Éds), Factors in the transfer of technology (p. 219-237). Cambridge : MIT Press.

Shane, S., Venkataraman, S. (2003). Guest editors' introduction to the special issues on technology entrepreneurship. Research Policy, 32, 1p. 81-184.

Shook, C., Priem, R. L., McGee, J. E. (2003). Venture creation and the enterprising individual: a review and synthesis. Journal of Management, 29, p. 379-399.

Tesfaye, B. (1997). Patterns of Formation and Development of High-Technology Entrepreneurs. In: D. Jones-Evans \& M. Klofsten (Eds.), Technology, Innovation and Enterprise - The European Experience (pp. 61-106). London: Macmillan Press.

Vesper, K. H. (1990). New Venture Strategies (éd. rév.). Englewood Cliffs: Prentice Hall.

Vohora, A., Wright, M., \& Lockett, A. (2004). Critical junctures in the development of university high-tech spinout companies. Research Policy, 33(1), 147-175. 


\title{
COMPARATIVE STUDY BETWEEN THE CREATION PROCESS OF TECHNOLOGICAL AND TRADITIONAL COMPANIES
}

\begin{abstract}
This article aims to compare the process of setting up technological companies with traditional ones and to identify the features of the process used by the first group. A model dividing the creation process into four stages (initiation, preparation, launch and consolidation) was designed and used as a framework for analysis. Two questionnaires were completed by 192 entrepreneurs of new companies, with 77 technological companies and 115 traditional ones represented. The results of the comparison between the two groups indicate that the process of creation from technology companies has certain peculiarities, more specifically that: (i) the access to financial resources as well as financial management constitute a big challenge to technological entrepreneurs, (ii) technological entrepreneurs need to develop their competences in management and commercialization, (iii) the process of creation of technological companies is longer and harder than that of traditional ones, (iv)market analysis represents a challenge for technological entrepreneurs; (v) there is a significant difference between the process of creation of the different groups of technological companies. These differences need to be considered when planning future research and subsidizing future entrepreneurs.
\end{abstract}

Key-words: Technological entrepreneurship; Venture creation process; high-tech entrepreneurs.

Data do recebimento do artigo: 09/11/2009

Data do aceite de publicação: 04/05/2010 